\title{
Research on the Current Situation and Problems of Intergenerational Family Education
}

\author{
Yongyi Li \\ School of Cardiff, Cardiff University School of Music, CardiffCF103AT, United Kingdom \\ LiY274@Cardiff.ac.uk
}

\begin{abstract}
Intergenerational education has become a relatively common social phenomenon in today's society. Family education has an important impact on the physical and mental health of children, so this article will study this phenomenon and put forward relevant suggestions and solutions from four aspects: parents, grandparents, government, and schools.
\end{abstract}

Keywords: Intergenerational Education; Family Education; Children's Psychology.

\section{Introduction}

With the rapid development of the current era, there are two educational models at this stage. The first is the education model of parents to their children. The other is the education model of grandparents to grandchildren. As the society develops faster, the life pressure of young parents is greater, and more and more grandparents join the parenting work, leading to the phenomenon of parent-grandparents co-parenting, and this education mode is called intergenerational education . Judging from the current educational work situation, intergenerational education has become a very important educational model. Although inter-generational education reduces the pressure on children's parents to some extent, while enjoying the benefits of inter-generational education, we should also pay close attention to the impact of inter-generational education on children's mental health. Because the education methods and concepts of the two generations will have a certain impact on the children's psychology, the children's education should be corrected and improved in time, and scientific education methods should be used to make the children grow up healthily.

\section{Core Concepts and Theoretical Basis}

\subsection{Definition of Intergenerational Education}

Although intergenerational education is very common in today's society, there is still no clear definition for the interpretation of "intergenerational education". Through research and summary, this article found that there are the following main types: (1) Intergenerational education is defined by "whether parents and grandparents participate together". Li Yang and Zeng Bin (2016) believe that intergenerational education is the independent care of grandchildren by grandparents. Kong Ping and Wang Yuxiang (2014) believe that inter-generational education is the raising of grandchildren by grandparents alone or with their parents. Que Pan (2011) divides intergenerational education into two categories: complete intergenerational education and incomplete intergenerational education. Completely separated education means that parents are separated from children for a long time, and grandchildren's daily life and education are completely taken over by grandchildren. For example, left-behind children whose parents go out to work. Incomplete intergenerational education means that parents and children are separated temporarily, grandparents only temporarily assume the responsibility of parenting, or grandparents live together with their parents to raise their grandchildren. For example, "Weekend Parents", when the parents need to go out, the children are mainly taken care of by the grandparents, and when the parents are free on the weekends, the children will be taken care of by the parents. (2) Intergenerational education is defined in terms of "the length of time that ancestors participated in caring for children". Some studies believe that grandparents only need to participate in taking care of their grandchildren as intergenerational education, while some studies believe that grandparents take care of their grandchildren for more than half a year to be called 
intergenerational education (Qi Haiyan, Zhu Jiacun, 2010). Xu Weiyun and Xu Lulu (2018) divide intergenerational education into three categories: intergenerational education dominates, grandparents spend significantly more time taking care of children than parents; intergenerational education aids, grandparents take care of the same time as their parents; no intergenerational education, Grandparents do not participate in taking care of grandchildren. (3) Intergenerational education is defined in terms of "parenting responsibilities undertaken by ancestors and fathers". Some researchers believe that intergenerational education is that parents completely give up the responsibility of raising children, and grandparents bear all or most of the responsibility for raising children, while some researchers believe that intergenerational education means that grandparents participate in raising their grandchildren and only bear part of the responsibility of raising children. (Duan Feiyan, Li Jing, 2012)[1].

\subsection{Theoretical Basis}

\subsubsection{Children's Psychological Development}

The research on children's psychological development has a history of more than 100 years. This process can be roughly divided into three stages. The first stage is a period of conceptual change, that is, a period of controversy over the concept and definition of children's psychological development. ; The second stage is the period of psychology practice in the education category; the third stage is the sublimation stage of perfecting the theory, which is the formation and development period of the scientific system of child psychology. Among them, Piaget, a well-known child psychologist, through research and observation of children's behavior, for the first time scientifically and systematically put forward the theory of children's cognitive development from birth to adult.

Piaget is committed to the study of children's psychological development, especially his theory of children's cognitive development, which gives a detailed and precise overview of how children understand the world and how to think about problems. In his theory, the process of children's psychological development needs to be assimilated and adapted, and the adaptation process of their psychological activities from balance-imbalance-balance is the real cause of psychological development. Among them, due to the interaction of different development factors, children's psychological development has a certain stage, and the characteristics that mark a certain age stage are through the differences in environment, education, culture, and subjective motivation[2]. Therefore, his theory provides useful theoretical guidance for this article to analyze the psychological impact of intergenerational education on children and the solutions.

\section{Literature Review}

\subsection{Research on the Causes of Intergenerational Education}

Intergenerational education is not common in foreign education. A study conducted by the London School of Education in the United Kingdom conducted a survey of 4,800 children born in the United Kingdom from 2000 to 2001, and compared the two very different growth environments of children who went to nursery during their early childhood and that they were handed over to grandparents for care and care. The impact. The results of the survey showed that it is better to hand over the children to professional institutions than to hand over the children to their ancestors. Because the older generation cannot provide children with educational knowledge and social communication environment that keeps pace with the times. Because the children who go to the nursery are better able to adapt to the collective life of people who are different from them, and they know how to socialize with their peers. At the same time, instead of handing over the children to their ancestors, it is better to hand them over to professional preschool teachers. The children can get a better and more standardized education environment, and they can also cultivate a regular life and rest. These are the elders of the older generation. Can not be provided to children. Therefore, the government is taking measures in this regard to help families whose children are taken care of by their ancestors [3]. 
In the eyes of foreign scholars, there are two major factors that cause intergenerational education, one is social factors and the other is family problems. Intergenerational education in foreign countries is caused by many factors, including the inability of the children's parents to afford the financial ability to raise their children, and going out to work, causing grandparents to take on the responsibility of taking care of children voluntarily or involuntarily. In addition, the causes of intergenerational education also include a series of factors such as parental alcoholism, drug abuse, crime, death, infectious diseases, and child abuse[4].

The reasons for the formation of inter-generational education in China are also very complicated, but it is still concentrated on the parents' need to go out for work. Since the reform and opening up, my country's modernization process is developing rapidly. With the reform of today's market economy and opening to the outside world, my country's young and middle-aged labor force will also be faced with complex work pressures. As a result, young parents need to devote a lot of energy to their own careers and have no time to take care of their children. It is safer and safer to leave it to your own parents to take care of your children than to take care of your children.

\subsection{Analysis of the Advantages and Disadvantages of Intergenerational Education}

\section{(1) Advantages}

According to research by domestic scholars, inter-generational education has the following advantages. First of all, grandparents have plenty of time and energy. Compared with young parents, they have a certain degree of parenting experience and life experience. If these are used reasonably, this will greatly help children's growth. Children's physical and mental health has a positive impact. Especially the social experiences and values learned by the elders in the social environment can promote the development of children's behavior and solve the problems encountered in educating children.

(2) Disadvantages

The thinking of the older generation can not keep up with the development of today's society, so there are certain outdated concepts and outdated educational methods of parenting, which cause the quality of children's education to decline. At the same time, Li Hongzeng scholars have investigated some family diseases of intergenerational education, conducted a comprehensive analysis of the shortcomings of the intergenerational education family, and came to a conclusion that the older generation's grandparents completely spoiled children It is the biggest drawback of inter-generational education [5]. Therefore, despite the fact that intergenerational education has certain advantages for the growth of children, on the whole, the disadvantages outweigh the advantages. And scholar Lu Lezhen also applauded that there are four different types of malpractices in inter-generational education. First, the elderly will choose sensibility in the grasp of sensibility and reason; second, they choose material in material and spirit; third, they tend to be quiet in terms of liveliness and quietness. The most important and last point is that it is easy to disagree with parents in terms of educational philosophy [6].

\subsection{The Impact of Intergenerational Education on Children's Psychological Development}

(1) The influence of inter-generational education on children's emotions, emotions and behaviors

Inter-generational upbringing is prone to adversely affect children's emotions and behaviors. Children who are up-bred to each other are prone to anxiety, insecure emotional problems, developmental delays and behavioral splitting problems, as well as inattention.

(2) Inter-generational upbringing has an adverse effect on children's psychology

After the parents leave the family and go out to work, for the children, the identity of the grandparents has changed from a facilitator to a guide. Therefore, the interaction between the grandparents and grandchildren before becomes particularly important, and it will have an extremely important effect on the children's psychological development influence. However, studies have shown that there are obvious differences in personality between children from intergenerational parenting families and children from parental parenting families. Children from intergenerational 
Volume 3 (2021)

parenting families show more personality defects such as hysteria, suspected illness, paranoia, and splitting [7].

(3) Inter-generational upbringing affects children's studies

Children under inter-generational education are very prone to the problems of being tired of studying and having unsatisfactory grades. Chen Huixiang (2005) found that the grades of the students from the inter-generational guardianship family were very unsatisfactory through the survey of the rural junior high school headteacher: excellent was $32.15 \%$, the middle was $33.61 \%$, and the poor was $34.24 \%$, which means that the students who were guarded by the inter-generation had a high school performance. Those who are at the middle or lower level reach more than two-thirds, which is far from the requirement of the normal distribution of students' academic performance[8].

\subsection{Measures to Optimize Family Education Across Generations}

\subsubsection{The Government Increases Financial Investment}

Improve the protection system for children's education, provide financial subsidies to families with inter-generational education, and reduce the economic pressure on young parents, especially in remote mountainous areas and economically backward areas.

\subsubsection{Mutual Cooperation between Family Members}

Parents and grandparents should cooperate with each other and set their own positions. Parents of children should take the initiative to take the primary responsibility for the upbringing and education of their children. While respecting the ancestors and giving play to the advantages of intergenerational education, they must coordinate the relationship between intergenerational education and parent-child education, form educational synergy, and implement "cooperative education" for their children. "This is an unshirkable responsibility of parents. Therefore, no matter how busy parents are at work, they must strive to spend more time with their children, cultivate the relationship with the children, and guide the children to grow up healthily. Blindly relying on the elderly to raise and educate the children and treating the elderly as free babysitters are not only disrespectful and disrespectful to the parents, but also irresponsible to the children.

In the family, the many limitations of inter-generational education often come from the grandparents' parents and their parents' independent and independent affairs. For parents of grandparents, due to their long-term work experience, rich social experience, and a lot of social experience, they do have "experience" in family education, but at the same time they are likely to fall into the misunderstanding of empiricism; Compared with them, the parents' education level is higher, their ideological concepts are more modern, and their theoretical knowledge in educating their children is quite rich, but they lack practical experience, and superstitious books and knowledge tend to become dogmatic. In fact, family education most needs the organic combination of the two, to learn from each other's strengths, to narrow the distance between grandparents and parents, to fill the generation gap between parents, and to provide children with a more complete education while complementing each other.

\subsubsection{Schools Play a Full Role}

Strengthen the cooperation between family education and school education, and give full play to the educational role of schools and teachers. Parents should pay attention to the impact of school education on the growth of their children, and extend the scope of school education to each child's family. Get involved and improve the shortcomings of inter-generational family education. School education not only transfers knowledge to children, but more importantly, cultivates children's various abilities, enhances children's moral cultivation, and improves children's spiritual life.

Schools for the elderly should also open relevant courses to follow up the ideas of the elderly and allow them to fully reflect through social phenomena. This is of great help to the grandparents and their parents in teaching their children in the family. 
Volume 3 (2021)

\section{References}

[1] Furong Lu, Yujing Song, Lupei Liu, The impact of intergenerational education on grandchildren and grandparents: the double-edged sword effect. Advances in Psychological Science. 2020.

[2] Huang Biling. Understand the cognitive development of children and accompany the healthy growth of children --Family education based on Piaget's cognitive development stage theory. Modern Vocational Education. (2017) No.15.

[3] British research shows that _intergenerational education is not as good as sending children to nurseries, ideological and theoretical education, (2009) Vol. 05. No15.

[4] Duan Feiyan, Li Jing. A review of research on inter-generational education at home and abroad in the past ten years. Journal of Shanghai Educational Research. 2012.

[5] The characteristics of the main nurturers of the grandfathers and the intergenerational education. Chinese family education, (2005) Vol.000. No01. p.12-16.

[6] Lule Zhen. Intergenerational education: a problem that needs attention. Family Education.2004, Vol. 10. Journal of Shanghai Educational Research. 2012.

[7] Duan Feiyan, Li Jing. Summary of research on inter-generational education at home and abroad in the past ten years.

[8] Chen Huixiang, Qi Wunian. The growth of left-behind children in rural areas urgently needs the care of their parents. Contemporary Education Forum, 2005, Vol5. 